\title{
CIRCUNSCRIPCIÓN DE TILLANDSIA CHAETOPHYLLA MEZ Y DESCRIPCIÓN DE TILLANDSIA SESSEMOCINOI (BROMELIACEAE: TILLANDSIOIDEAE)
}

\author{
Ana Rosa López-Ferrari ${ }^{1}$, Adolfo Espejo Serna ${ }^{1}$ y \\ Paloma Blanco Fernández de Caleya ${ }^{2}$
}

${ }^{1}$ Universidad Autónoma Metropolitana-lztapalapa, División de Ciencias Biológicas y de la Salud, Departamento de Biología, Herbario Metropolitano, 09340 México, D.F. aes@xanum.uam.mx

${ }^{2}$ Real Jardín Botánico, Consejo Superior de Investigaciones Científicas

Plaza de Murillo 2. E-28014, Madrid, España

blancofc@ma-rjb.csic.es

\section{RESUMEN}

Se discute y aclara la situación nomenclatural de Tillandsia chaetophylla Mez y se describe como nueva para la ciencia e ilustra a T. sessemocinoi López-Ferrari, Espejo et P. Blanco. Se aportan datos sobre la distribución y la fenología de ambas especies.

Palabras clave: Bromeliaceae, México, Tillandsia.

\begin{abstract}
The nomenclatural status of Tillandsia chaetophylla Mez is discussed and clarified, and a new species, Tillandsia sessemocinoi López-Ferrari, Espejo et P. Blanco, is described and illustrated. Data concerning the distribution and phenology of both taxa are provided.

Key words: Bromeliaceae, Mexico, Tillandsia.

\section{INTRODUCCIÓN}

De los numerosos nombres usados para designar a las especies mexicanas del género Tillandsia L., muchos fueron propuestos en los siglos XVIII y XIX por botánicos europeos, y consecuentemente, los tipos nomenclaturales de dichos taxa
\end{abstract}


se depositaron en herbarios del viejo continente. Algunos ejemplares se perdieron durante la segunda guerra mundial, otros todavía no han sido localizados y muchos más tienen detrás largas historias de confusiones nomenclaturales, ya que en su momento no fueron debidamente etiquetados y/o resguardados. Lo anterior, entre otras cosas, ha dificultado durante mucho tiempo la aplicación correcta de los nombres de varios taxa mexicanos de Tillandsia. Un ejemplo de lo anterior es el caso de la especie que aquí nos ocupa: Tillandsia chaetophylla Mez.

Al integrar el manuscrito de las Bromeliaceae para la Flora del Bajío y Regiones Adyacentes, nos llamaron la atención algunos ejemplares provenientes de los alrededores de Morelia identificados como Tillandsia chaetophylla. Dicho taxon fue descrito por Mez (1896, p. 726) quien en el protólogo del mismo cita tres colecciones, a saber: Jürgensen 13, Karwinsky s. n. y Pavón s. n. depositadas en los herbarios BM, FI, M y W (Holmgren et al., 1990), aunque no indica con precisión qué ejemplar vió en cada colección. Smith (1951, p. 481) lectotipificó la especie, seleccionando para ello el pliego del herbario Pavón depositado en BM, el cual carece de datos relativos al colector, número de recolección y localidad; sin embargo, en la etiqueta original se distingue claramente la caligrafía de Martín de Sessé (1751-1808), director de la Real Expedición Botánica a la Nueva España (1787-1803) quien escribe "6-1 / Tillandsia / subulata / sp. n.". Como ya han explicado distintos autores, entre los que destaca McVaugh (1977, 2000), José Pavón Jiménez (1754-1840), uno de los botánicos de la Expedición al Virreinato de Perú y Chile (1777-1787), tuvo acceso a las colecciones mexicanas depositadas en la Oficina de la Flora Americana en Madrid, y desde 1814 hasta poco antes de su muerte, vendió y regaló parte de ellas a diferentes botánicos y coleccionistas europeos, quienes las distribuyeron a distintas instituciones botánicas (Blanco Fernández de Caleya, 2000). Por lo anteriormente expuesto, concluimos que el espécimen depositado en BM (Pavón s. n.) procede sin duda del material colectado durante la expedición a la Nueva España.

Dado que el recorrido de la tercera excursión de esa Real Expedición (McVaugh, 1977; Maldonado y Puig-Samper, 2000) tocaba puntos cercanos a Morelia, cabía suponer que el material tipo de Tillandsia chaetophylla podría provenir de dicha zona y corresponder a los especímenes que llevan el nombre de T. acerosa, depositados en el Real Jardín Botánico de Madrid (MA), institución donde se encuentra la colección más completa de los ejemplares obtenidos en el mencionado esfuerzo exploratorio denominada "Herbario Sessé y Mociño". Se trata de dos pliegos posteriormente determinados como T. chaetophylla Mez, pero que en sus etiquetas originales manuscritas, en un caso por José Mariano Mociño (1757-1820) quien participó destacadamente en esta expedición, y en el otro por 
el farmacéutico Jaime Senseve (?-1805) se puede leer: "6-1 / Tillandsia acerosa". Asimismo, hay otro duplicado de dicha colección en el Field Museum (F) anotado originalmente como "Tillandsia acerosa" por José Demetrio Rodríguez, quien ayudó a Mariano Lagasca en el arreglo de las colecciones de Sessé y Mociño depositadas en el Real Jardín Botánico (MA), copiando las determinaciones originales de estos dos mencionados miembros de la expedición.

Tanto el espécimen de BM como los dos de MA y el de F, son indudablemente la misma especie, aunque no está claro que se trate de una sola recolección, ya que las etiquetas originales no llevan datos de localidades y no coinciden en la determinación original, la cual es de hecho la única información disponible.

El análisis de los documentos originales de la expedición, depositados en el archivo del Real Jardín Botánico de Madrid, relativos al género Tillandsia, no aclara cuál fue la primera determinación que Sessé y Mociño pudieron asignar a esta especie. Entre los legajos existen dos relaciones manuscritas por un copista (ARJBM V, 5, 1 págs. 127 y 129); en la primera de ellas aparece, entre otras, la entrada "Acerosa. Tillands. Foliis filiformibus integerrimis spica paniculata laxa. Desc." y en la segunda está tachado el acceso "Acerosa. Tillandsia foliis acerosis".

En el Herbario de Madrid existe otro pliego más de Tillandsia, en el cual aparece manuscrito el epíteto "subulata" y que tiene el número 5450 adjudicado por Cuatrecasas (MA600160, negativo del Field Museum $\mathrm{n}^{\circ}$ 41781) (cf. Blanco Fernández de Caleya, 2000). En la etiqueta de este ejemplar aparece escrito: "61 / Fillandsia / subulata / N." y en el reverso de la misma puede leerse "6-1 / Tillandsia / tenuifolia / [m. Sessé:] Corrige Sino / nom. Jacq. / tab. mala". Este material corresponde en realidad a Tillandsia filifolia Schltdl. \& Cham. y fue anotado como tal por Lyman B. Smith el 12 de septiembre de 1936.

Es importante mencionar que los epítetos específicos "acerosa" y "subulata", no fueron ni válida ni efectivamente publicados en las obras de Sessé y Mociño (1893, 1894).

De acuerdo con lo antes expuesto, la forma adecuada de citar la lectotipificación hecha por Smith (1951) es la siguiente: Tillandsia chaetophylla Mez, in C. DC., Monogr. Phan. 9: 726-727. 1896. Lectotipo: M. Sessé y J. M. Mociño s. n., distribuido por J. Pavón (BM!).

Cabe señalar aquí que el nombre válido Tillandsia subulata Vell. (Vellozo, 1825 [i. e. 1829]) corresponde a una planta brasileña que no crece en México. A su vez, el de T. subulata E. Morren ex Baker (1889), publicado sin descripción alguna y como sinónimo de T. vestita Schltdl. \& Cham. (= T. schiedeana Steud.) con base en un ejemplar recolectado por Uhde con el número 182 y depositado en $\mathrm{B}$, es un 
nombre inválido, y que en todo caso no se podría usar por ser homónimo posterior (Greuter et al., 2000).

La revisión de numerosos ejemplares herborizados, así como el estudio de las plantas en condiciones naturales, nos ha permitido distinguir dos taxa a los cuales se les ha aplicado el nombre de T. chaetophylla. Uno de ellos proviene del oriente del país, de los estados de Oaxaca y Veracruz, mientras que el otro se encuentra en el centro-occidente de la república, en los estados de México, Morelos, Michoacán y Jalisco (Fig. 1). Aunque a primera vista podrían confundirse, existen entre ellos diferencias claras (Cuadro 1, Fig. 2).

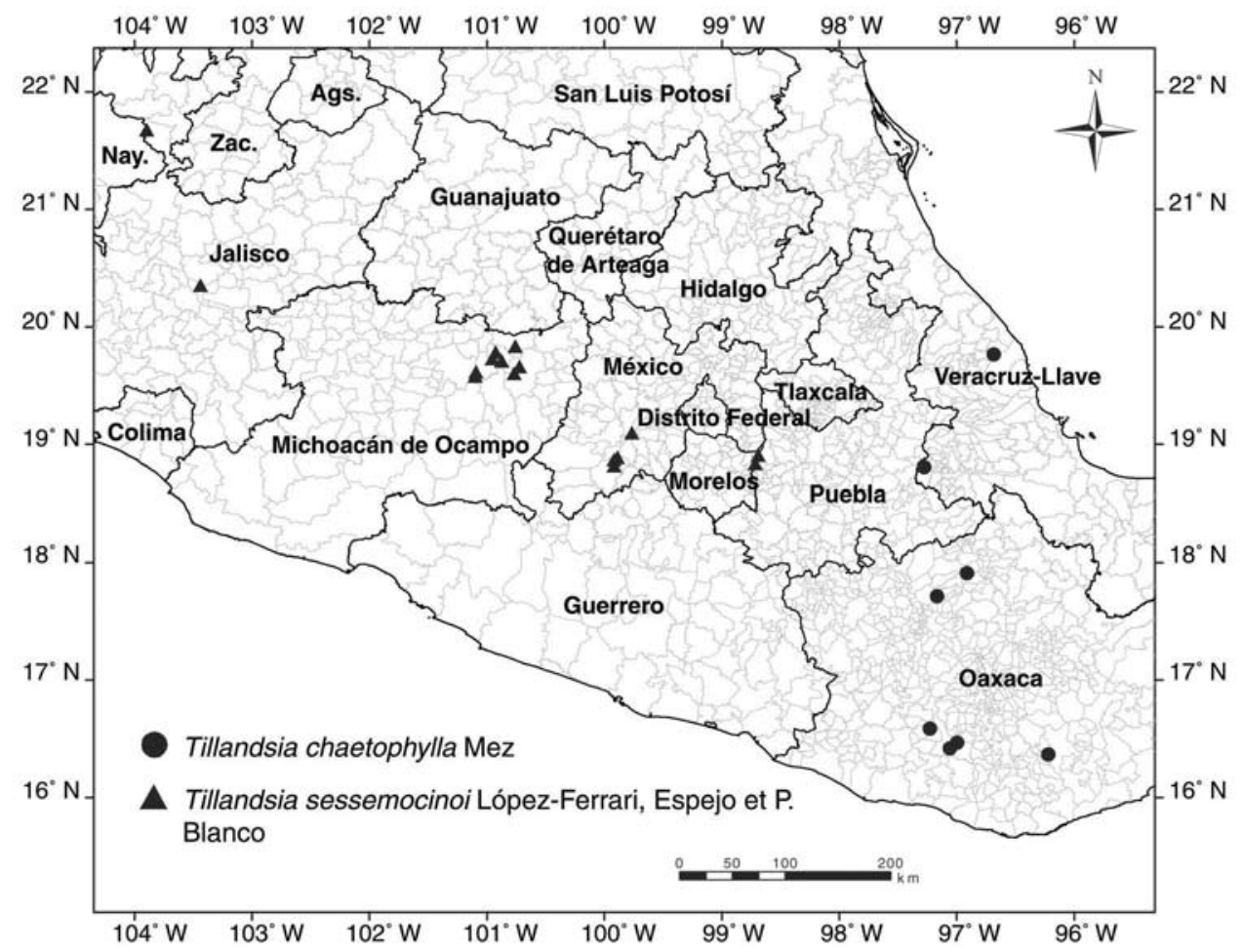

Fig.1. Distribución conocida de Tillandsia chaetophylla Mez y de T. sessemocinoi LópezFerrari, Espejo et P. Blanco

Las poblaciones procedentes de Oaxaca y Veracruz, son las que corresponden con el lectotipo de Tillandsia chaetophylla y coinciden también con los ejemplares de Jürgensen 13 (FI, G-DEL, OXF) y de Karwinsky s. $n$. (M), citados por Mez en 
Cuadro 1. Comparación de T. chaetophylla Mez y T. sessemocinoi López-Ferrari, Espejo \& P. Blanco.

\begin{tabular}{|l|l|l|}
\hline & \multicolumn{1}{|c|}{ T. chaetophylla Mez } & \multicolumn{1}{|c|}{$\begin{array}{c}\text { T. sessemocinoi López-Ferrari, } \\
\text { Espejo \& P. Blanco }\end{array}$} \\
\hline Tamaño planta & 24-30 cm de alto & $(35) 40-46 \mathrm{~cm}$ de alto \\
\hline Láminas foliares & de $0.5-1 \mathrm{~mm}$ de ancho & de 3-4(6) mm de ancho \\
\hline Espiga & $\begin{array}{l}\text { de } 3.5-5.5 \mathrm{~cm} \text { de largo, con 3- } \\
\text { 4(5) flores }\end{array}$ & $\begin{array}{l}\text { de 7-9 } \mathrm{cm} \text { de largo, con 5-8 } \\
\text { flores }\end{array}$ \\
\hline Brácteas florales & de 2.2-2.5 2.7$) \mathrm{cm}$ de largo & de (3.3)3.5-4 cm de largo \\
\hline Corolas & $\begin{array}{l}\text { hipocraterimorfas, de } 6.5-6.8 \mathrm{~cm} \\
\text { de largo, estambres inclusos }\end{array}$ & $\begin{array}{l}\text { tubiforme-urceoladas, de } 4.5-5.2 \\
\mathrm{~cm} \text { de largo, estambres exertos }\end{array}$ \\
\hline
\end{tabular}

la descripción original de este taxon, y es por lo tanto a las que debe aplicarse este nombre (Fig. 1).

En consecuencia, el material seleccionado como lectotipo de Tillandsia chaetophylla fue probablemente recolectado por Mociño en la Mixteca o en Veracruz, durante la expedición al sudeste a principios de 1793 (McVaugh, 1977) y no en los alrededores de Morelia, como habíamos supuesto en un principio. A continuación incluimos una descripción actualizada de esta especie.

Tillandsia chaetophylla Mez, in C. DC., Monogr. Phan. 9: 726-727. 1896. Tipo: México, Oaxaca, from Trapiche de Santa Ana, VII.1846, C. Jürgensen 13 (sintipos: FI!, G-DEL!, OXF!); sin localidad precisa, Karwinsky s. $n$. (sintipo: M!); M. Sessé \& J. M. Mociño s. n., distribuido por Pavón (lectotipo: BM!). Fig. 2 A.

Hierbas arrosetadas, epífitas, en flor de 24 a $30 \mathrm{~cm}$ de alto, las rosetas de tipo escoba, cilíndricas, de 1 a $1.5 \mathrm{~cm}$ de diámetro en su base, cespitosas, acaules. Hojas numerosas, las vainas pardas oscuras, blancas y papiráceas en la base, triangulares, de 1 a $1.5 \mathrm{~cm}$ de largo por 6 a $7 \mathrm{~mm}$ de ancho, densamente pardolepidotas en ambas superficies, las láminas verdes oscuras, filiformes, involutas, de 15 a 20 (25) $\mathrm{cm}$ de largo por 0.5 a $1 \mathrm{~mm}$ de ancho, densamente punctulado-lepidotas, atenuadas en el ápice. Inflorescencias terminales, erectas, simples, el escapo linear, de 15 a $20 \mathrm{~cm}$ de largo por ca. $1.5 \mathrm{~mm}$ de diámetro, cubierto totalmente por las vainas de las brácteas; brácteas del escapo foliáceas, las vainas rosadas, oblongotriangulares, de 2 a $2.5 \mathrm{~cm}$ de largo, las láminas verdes, filiformes, de 4 a $7.5 \mathrm{~cm}$ de largo, disminuyendo de tamaño gradualmente hacia la parte distal del escapo, la 

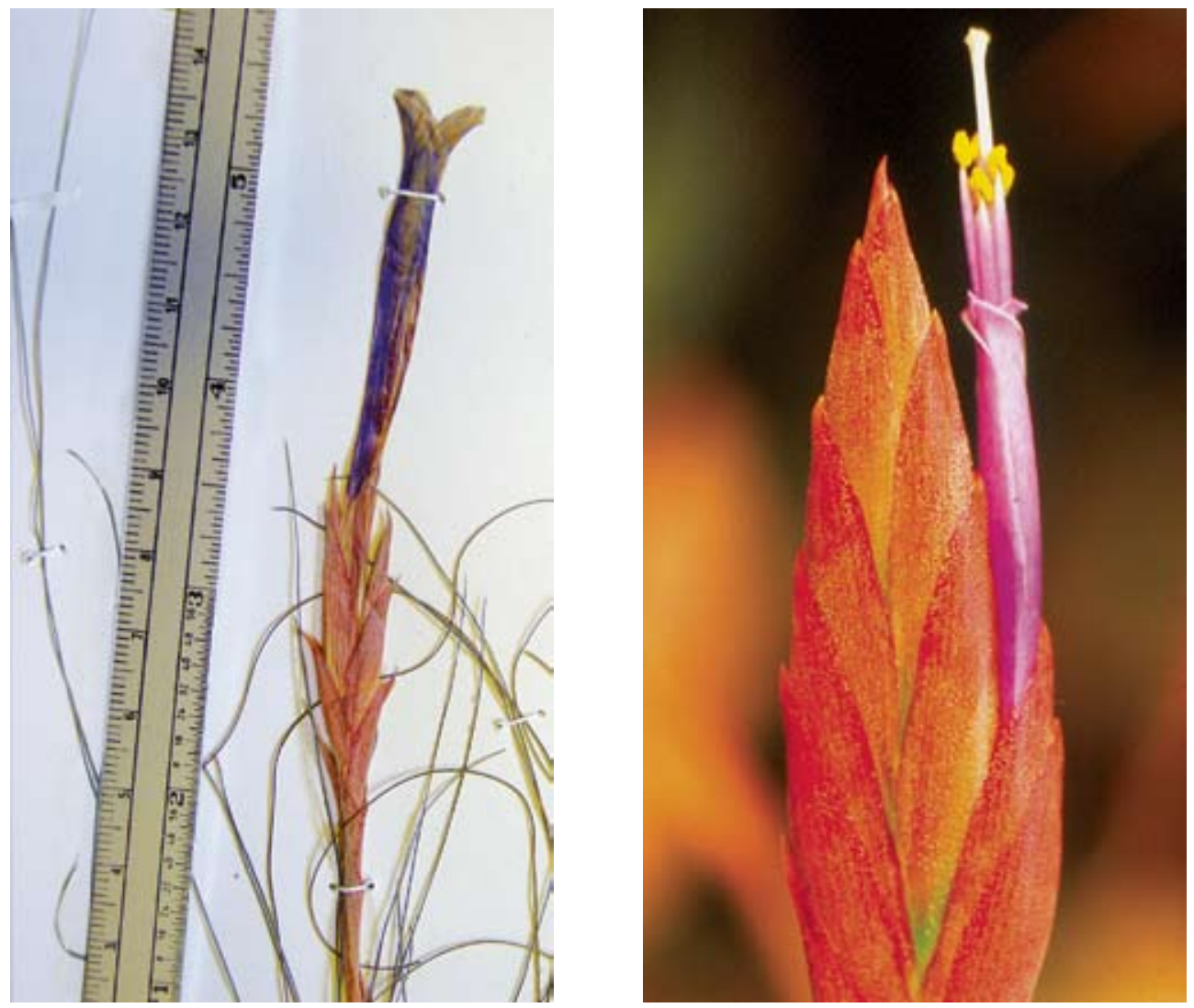

Fig. 2. A. Tillandsia chaetophylla Mez. (detalle del ejemplar: A. Salinas y E. Martínez 5980 (MEXU) B. Tillandsia sessemocinoi Espejo, López-Ferrari y Blanco (fotografía de la espiga correspondiente al espécimen: A. R. López-Ferrari et al. 2780).

espiga oblonga a oblongo-elíptica, aplanada, de 3.5 a $5.5 \mathrm{~cm}$ de largo por 1 a $1.3 \mathrm{~cm}$ de ancho; brácteas florales rosadas, oblongo-lanceoladas, de 2.2 a $2.5(2.7) \mathrm{cm}$ de largo por 8 a $10 \mathrm{~mm}$ de ancho, más largas que los entrenudos, imbricadas, nervadas, ecarinadas, lepidotas, acuminadas y excurvadas en el ápice; flores dísticas, erectas, 3 a 4(5) por espiga, actinomorfas, subsésiles, formando una corola hipocraterimorfa; sépalos verdes, angosta y largamente lanceolados, de 3 a $3.2 \mathrm{~cm}$ de largo por 3.5 a $4 \mathrm{~mm}$ de ancho, nervados, glabros, con un amplio margen hialino, largamente atenuados a acuminados en el ápice, los dos posteriores carinados y connatos en casi toda su longitud; pétalos libres, de color violeta, oblongo-espatulados, de 6.5 a $6.8 \mathrm{~cm}$ de largo por 6 a $7 \mathrm{~mm}$ de ancho, redondeados a agudos y excurvados en el 
ápice; estambres subiguales, más cortos que los pétalos, los filamentos blancos hacia la base, de color violeta hacia el ápice, linear-filiformes, de 6 a $6.5 \mathrm{~cm}$ de largo, las anteras amarillas, oblongas, de ca. $3 \mathrm{~mm}$ de largo; ovario verde, elipsoide, de ca. $7 \mathrm{~mm}$ de largo, estilo blanco, filiforme, de ca. 6.5 a $7 \mathrm{~cm}$ de largo, estigma blanco. Cápsula no vista; semillas no vistas.

Ejemplares examinados: Oaxaca: Municipio no indicado, an der Strasse von Puerto Escondido - Oaxaca, R. Ehlers 8290 (WU); Municipio de Villa Sola de Vega, $10 \mathrm{~km}$ después de Los Reyes, carretera Sola de Vega - Juquila, A. Espejo, A. R. LópezFerrari y J. Garcia-Cruz 5076 (CICY, CIIDIR, IEB, MEXU, UAMIZ); Municipio de Villa Sola de Vega, from Trapiche de Santa Ana, VII.1846, C. Jürgensen 13 (sintipos: BM, FI!, G-DEL!, OXF); Municipio de Villa Sola de Vega, along the road from Sola de Vega to Ojo de Agua, H. y L. Hromadnik 16078 (WU); Municipio de San Carlos Yautepec, Sierra de Lachevía "Lecheguía", E. Matuda y colaboradores 38439 (MEXU, MO); Distrito Pochutla, Municipio de San Pedro Pochutla, Cerro de la Virgen, B. P. Reko 6213 (GH); Distrito Nochixtlán. Municipio de San Miguel Huautla, El Boquerón, ca. $4 \mathrm{~km}$ al S de San Miguel Huautla y al oeste de Santa María Ocotlán. 17²4' N, 97¹0' W, A. Salinas T. y R. Martínez S. 5980 (MEXU); Municipio de Teotitlán de Flores Magón, an der Strasse von Teotitlán nach Huautla, bei km 25, S. Schatzl 77/98 (WU); Municipio de San Juan Bautista Cuicatlán, near Coyula, L. C. Smith $557(\mathrm{GH})$. Veracruz: Municipio de Alto Lucero de Gutiérrez Barrios, Cerro de la Cima, entre La Sombra y Tierra Blanca, $19^{\circ} \mathrm{N}, 96^{\circ} 41^{\prime} \mathrm{W}, \mathrm{G}$. Castillo y F. Vázquez 1591 (MEXU, XAL); Municipio de Chiconquiaco, cerca de la cascada de Rincón Grande, yendo hacia La Cumbre, M. Cházaro y J. Camarillo 3922 (XAL); Municipio de Maltrata, Maltrata, E. Matuda 1190 (MEXU).

Tillandsia chaetophylla crece como epífita en bosques de encino y de encinopino entre los 1700 y los $2200 \mathrm{~m}$ s.n.m. Florece de marzo a septiembre.

Por otra parte, las plantas procedentes de los estados de México, Morelos, Michoacán y Jalisco (Fig. 1) corresponden a un taxon no descrito para el cual proponemos el siguiente nombre:

Tillandsia sessemocinoi López-Ferrari, Espejo et P. Blanco, sp. nov. Figs. 2B, 3.

Herba epiphytica, acaulis, rosulata, florens (35)40-46 cm alta; folia numerosa, vaginae distinctae, triangulares, $1.5-2.6 \mathrm{~cm}$ longae, $1.2-1.7 \mathrm{~cm}$ latae; laminae lineari- 


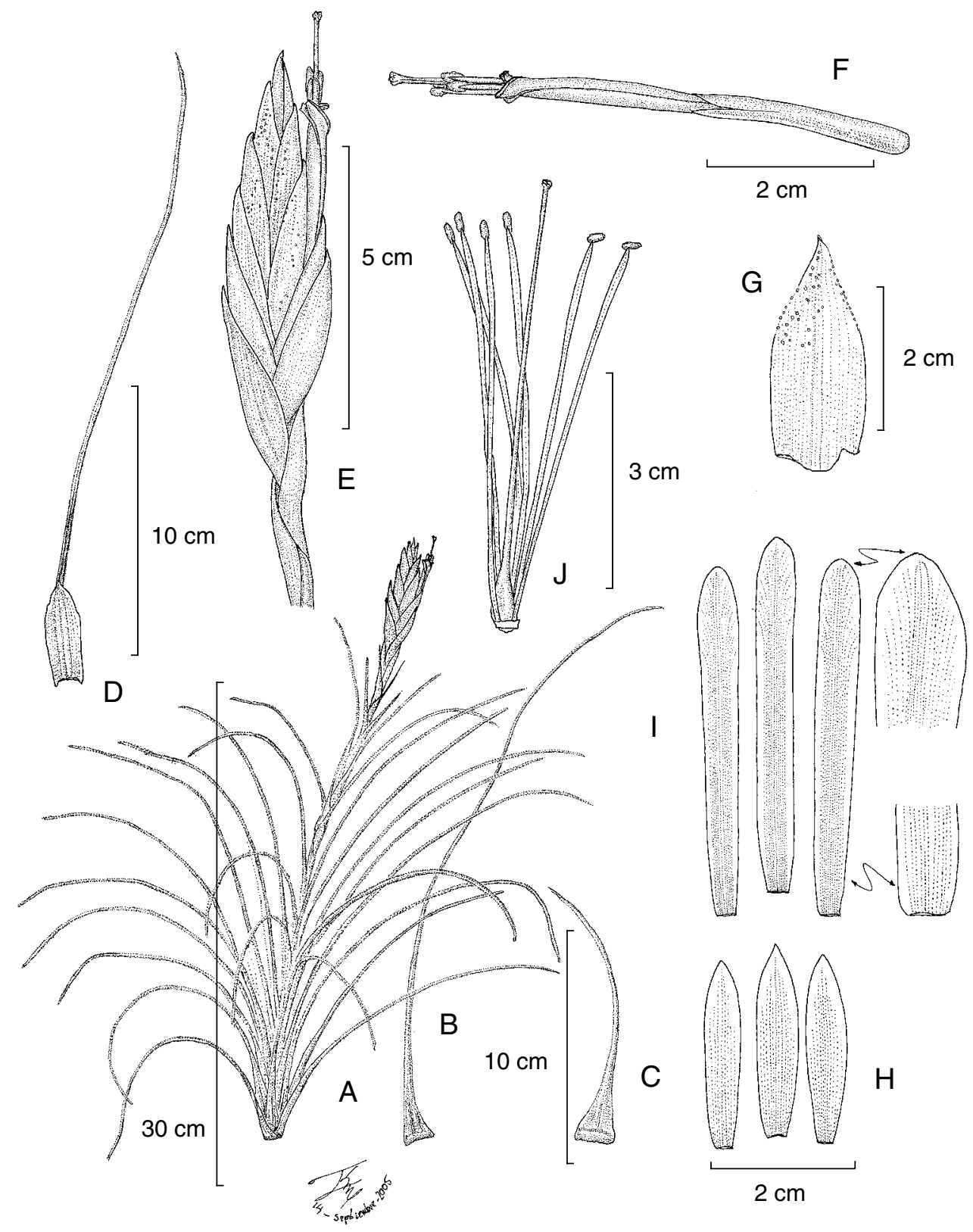

Fig. 3. Tillandsia sessemocinoi López-Ferrari, Espejo et P. Blanco. A. Hábito; B. Hoja; C. y D. Brácteas del escapo; E. Inflorescencia; F. Flor sin bráctea floral; G. Bráctea floral; H. Flor disecada, sépalos; I. Flor disecada, pétalos; J. Flor disecada, androceo y gineceo. 
filiformes, 19.5-36 cm longae, 3-4(-6) mm latae; scapus inflorescentiae erectus, teres, 21$37 \mathrm{~cm}$ longus; inflorescentia simplex; spica elliptica ad oblongo-elliptica, 7-9 cm longa, $1.5-2.5 \mathrm{~cm}$ lata; bracteae florales distichae, imbricatae, oblongo-ellipticae, (3.3-)3.5-4 cm longae, $1.2-1.5 \mathrm{~cm}$ latae, ecarinatae, lepidotae; corolla tubiformi-urceolata; petala 4.5-5.2 $\mathrm{cm}$ longa, 4.5-7.5 mm lata, violacea; stamina et stylus exserta.

Hierba epífita, en flor de (35)40 a $46 \mathrm{~cm}$ de alto, cespitosa, las rosetas escobiformes, cilíndricas, de 2.4 a $3 \mathrm{~cm}$ de diámetro en su base, acaules. Hojas numerosas, las vainas pardas oscuras y con una banda basal oscura y lustrosa por fuera, blancas y papiráceas en la base por dentro, triangulares, de 1.5 a $2.6 \mathrm{~cm}$ de largo por 1.2 a $1.7 \mathrm{~cm}$ de ancho, densamente pardo-lepidotas en ambas superficies, las láminas verdes oscuras, linear-filiformes, involutas, de 19.5 a $36 \mathrm{~cm}$ de largo por 3 a $4(6) \mathrm{mm}$ de ancho, densamente punctulado-lepidotas, atenuadas en el ápice. Inflorescencias terminales, erectas, simples, el escapo linear, de 21 a $37 \mathrm{~cm}$ de largo por 2.3 a $3 \mathrm{~mm}$ de diámetro, cubierto totalmente por las vainas de las brácteas; brácteas del escapo foliáceas, las vainas rosadas, oblongo-triangulares, de 2.5 a $4 \mathrm{~cm}$ de largo, las láminas verdes, linear-filiformes, de 15 a $25 \mathrm{~cm}$ de largo, disminuyendo de tamaño gradualmente hacia la parte distal del escapo, la espiga elíptica a oblongo-elíptica, aplanada, de 7 a $9 \mathrm{~cm}$ de largo por 1.5 a $2.5 \mathrm{~cm}$ de ancho; brácteas florales rosadas, oblongo-elípticas, de (3.3-)3.5 a $4 \mathrm{~cm}$ de largo por 1.2 a $1.5 \mathrm{~cm}$ de ancho cuando desdobladas y aplanadas, más largas que los entrenudos, imbricadas, nervadas, ecarinadas, lepidotas, acuminadas y excurvadas en el ápice; flores dísticas, erectas, 5 a 8 por espiga, actinomorfas, subsésiles; sépalos verdes con el ápice rosado, oblongo-lanceolados a elípticos, de 2.6 a $2.8 \mathrm{~cm}$ de largo por 5 a $6 \mathrm{~mm}$ de ancho, glabros, con un amplio margen hialino, atenuados en el ápice, los dos posteriores carinados y cortamente connatos en la base; pétalos libres, de color violeta en la mitad o los dos tercios superiores, blancos en la base, oblongos, de 4.5 a $5.2 \mathrm{~cm}$ de largo por 4.5 a $7.5 \mathrm{~mm}$ de ancho, agudos y excurvados en el ápice, formando una corola tubiforme-urceolada; estambres desiguales, más largos que los pétalos, los filamentos blancos hacia la base, de color violeta hacia el ápice, linearfiliformes, sinuados en la parte apical, de 5.4 a $5.9 \mathrm{~cm}$ de largo, las anteras amarillas, oblongas, de 2.5 a $3 \mathrm{~mm}$ de largo; ovario verde, ovoide, de ca. $6 \mathrm{~mm}$ de largo, estilo blanco, linear-filiforme, de 5.5 a $6.5 \mathrm{~cm}$ de largo, más largo que los estambres, estigma de color violeta. Cápsula no vista; semillas no vistas.

Tipo: Michoacán: Municipio de Queréndaro, $2 \mathrm{~km}$ después de Real de Otzumatlán, rumbo a Milpillas, A. R. López-Ferrari, A. Espejo, J. Ceja y V. A. 
Pulido E. 2780 (holotipo: UAMIZ 52291; Isotipos UAMIZ 50387, UAMIZ 50384, IEB 146431).

Paratipos: Jalisco: Municipio de Jocotepec, Cerro Viejo, al N de Zapotitlán de Hidalgo, base SE del promontorio rocoso denominado El Gachupín, $J . J$. Guerrero N., M. Cházaro B. y J. A. Machuca N. 697 (IBUG, MICH); Municipio de Jocotepec, Cerro Viejo, paraje Barranca del Agua, enfrente de Zapotitán de Hidalgo, J. A. Machuca N. 452 (XAL); Municipio de Jocotepec, Cerro Viejo, al N de Zapotitán, vereda de La Nariz a la Barranca del Agua, J. A. Machuca N. 6337 (IEB, UAMIZ, XAL); Municipio de Jocotepec, Cerro Viejo, paraje El Quinto, enfrente de Zapotitán, J. A. Machuca N. 6361 (IEB, MEXU, XAL); Municipio de San Martín de Bolaños, camino del Istafiate al Cordón, $30 \mathrm{~km}$ al W de San Martín, A. Flores Macías 1169 (IBUG(x2)). México: Municipio de Valle de Bravo, Valle de Bravo, R. Ehlers EM851414 (WU); Municipio de Almoloya de Alquisiras, Las Peñas de Texcalco, $10 \mathrm{~km}$ al SE de Almoloya de Alquisiras, M. Flores C. y F. Riveros 783 (UAMIZ); Municipio de Almoloya de Alquisiras, La Cantera, SE de Almoloya de Alquisiras, M. Flores C. 922 (UAMIZ); Municipio de Almoloya de Alquisiras, Cerro de Ahuacatitlán, Almoloya de Alquisiras, E. Matuda y colaboradores 30588 (MEXU); Municipio de Texcaltitlán, falda sur Nevado de Toluca, E. Matuda y colaboradores 30639 (MEXU). Michoacán: Municipio de Charo, between the Río del Salto and La Polvilla, ca. 18 miles east of Morelia, R. M. King y T. R. Soderstrom 5085 (MEXU); Municipio de Hidalgo, $19 \mathrm{~km}$ al O de Ciudad Hidalgo, J. C. Soto N. y S. Aureoles C. 7398 (MEXU); Municipio de Hidalgo, $2 \mathrm{~km}$ al S de Mil Cumbres, camino a San Antonio Villalongín, J. C. Soto N., S. Aureoles C., S. Conejo, G. Silva y C. Pizarras 8490 (IEB, MEXU); Municipio de Indaparapeo, cerro El Volantín, cerca del rancho Los Huertos J. S. Martínez 1265 (CIIDIR, IBUG, IEB, MEXU, UAMIZ, XAL); Municipio de Morelia, Cerro Azul, G. Arsène 5363 (MEXU, P); Municipio de Morelia, Cerro Azul, G. Arsène s. n. (P); Municipio de Morelia, près Morelia, G. Arsène s. n. (BR, P); Municipio de Morelia, Morelia, G. Arsène s. n. (P); Municipio de Morelia, aproximadamente $9.5 \mathrm{~km}$ después de San Miguel del Monte rumbo a Túmbisca, A. Espejo y A. R. López-Ferrari 4894 (IEB, UAMIZ); Municipio de Morelia, kurz E Morelia, L. Hromadnik y P. Schneider 12106 (WU); Municipio de Zinapécuaro, $4 \mathrm{~km}$ al E de Taimeo, sobre el camino a Maravatío, J. Rzedowski 46034 (IEB, MEXU); Municipio de Tlalpujahua, région montagneuse des environs de Toluca, S. Tlalpuhajua, M. L. Diguet s. $n$. (P(x3)); Municipio no indicado, Mil Cumbres, Morelia - Ciudad Hidalgo, R. Ehlers 851303 (WU). Morelos: Municipio Tetela del Volcán, $8.3 \mathrm{~km}$ sobre el camino Alpanocan (San Antonio Alpanoca) - El 
Salto, A. Espejo, A. R. López-Ferrari y R. Jiménez M. 5648 (UAMIZ); 5 km sobre la desviación a la cascada El Salto, a partir del camino Tetela del Volcán - Hueyapan, J. Santana C., L. Pacheco, Y. Sandoval, E. Callejas G. y A. Valdés R. 380 (UAMIZ); Nueva España, sin localidad precisa, M. Sessé y J. M. Mociño s. n. (F 848637!, MA 600158 ! numerados previamente por Cuatrecasas como 5443, MA606714! numerado posteriormente por Paloma Blanco como PB-195).

Otros registros: Michoacán: Municipio de Charo, El Álamo, $1.9 \mathrm{~km}$ después de Los Cantiles, carretera Morelia - Ciudad Hidalgo, A. Espejo y A. R. López-Ferrari 4756 (diapositivas UAMIZ).

Tillandsia sessemocinoi prospera como epífita en bosques de encino, de pino-encino y mesófilos entre los 2100 y los $3500 \mathrm{~m}$ s.n.m. Florece de marzo a noviembre.

El nombre de la nueva especie se dedica a Martín de Sessé y Lacasta y a José Mariano Mociño, protagonistas de la Real Expedición Botánica a la Nueva España y promotores de la primera Flora Mexicana. Si bien los resultados de dicha expedición no fueron, por desgracia, publicados oportunamente, han aportado y seguirán aportando valiosos datos al conocimiento de las plantas tanto mexicanas como americanas (McVaugh, 1987).

\section{AGRADECIMIENTOS}

Deseamos expresar nuestra gratitud a Jerzy Rzedowski, Graciela Calderón de Rzedowski, Ginés López González y Ramón Morales por la revisión crítica del manuscrito y sus valiosos aportes al mismo, a Mar González Bausá por el apoyo brindado en la digitalización de imágenes de los pliegos de Sessé y Mociño, a Armando Butanda por su ayuda en algunos aspectos bibliográficos, a Nancy Martínez Correa por la elaboración del mapa que acompaña este trabajo y a los curadores de los siguientes herbarios BR, CICY, CIIDIR, ENCB, GH, IBUG, MA, MEXU, MICH, MO, OXF, P, UAMIZ, US, WU, XAL por las facilidades brindadas. La ilustración de la nueva especie fue elaborada por Rolando Jiménez Machorro. Parte de este trabajo fue realizado gracias a la beca Elizabeth Bascom, del Missouri Botanical Garden, otorgada a la primera autora en el año 2004. 


\section{LITERATURA CITADA}

Baker, J. G. 1889. Handbook of the Bromeliaceae. George Bell \& Sons. Londres. 243 pp. Blanco Fernández de Caleya, P. 2000. Colecciones históricas: El Herbario de la Real Expedición de Nueva España (1787-1803). Bol. Asoc. Herb. Ibero-Macaronésicos 5: $5-10$.

Greuter, W., J. McNeill, F. R. Barrie, H. M. Burdet, V. Demoulin, T. S. Filgueiras, D. H. Nicholson, P. C. Silva, J. E. Skog, P. Trehane, N. J. Turland y D. L. Hawksworth. 2000. International code of botanical nomenclature (Saint Louis Code). Koeltz Scientific Books, Konigstein. 474 pp.

Holmgren, P. K., N. H. Holmgren y L.C. Barnett (eds.). 1990. Index herbariorum. Part I: The herbaria of the world. New York Botanical Garden. 8a. ed. Nueva York. 693 pp.

Maldonado, J. L. y M. A. Puig-Samper. 2000. La aventura ultramarina de Sessé y Mociño. In: San Pío Aladrén, M. P. y M. A. Puig-Samper (eds.). El águila y el nopal, la expedición de Sessé y Mociño a Nueva España (1787-1803). Catálogo de los Fondos Documentales del Real Jardín Botánico de Madrid. Ed. Lunwerg / Real Jardín Botánico, Cajamadrid. Madrid. 229 pp.

McVaugh, R. 1977. Botanical results of the Sessé \& Mociño expedition (1787-1803). I. Summary of excursions and travels. Contr. Univ. Michigan Herb. 11: 97-195.

McVaugh, R. 1987. Botanical results of the Sessé \& Mociño expedition (1787-1803). III. The impact of this and other expeditions on contemporary botany in Europe. Contr. Univ. Michigan Herb. 16: 155-171.

McVaugh, R. 2000. Botanical results of the Sessé \& Mociño Expedition (1787-1803). VII. A guide to relevant scientific names of plants. Hunt Institute for Botanical Documentation, Carnegie Mellon University. Pittsburgh. pp. 102-104.

Mez, C. 1896. Bromeliaceae. In: de Candolle, C., Monogr. phan. 9: 1-990.

Sessé, M. y J. M. Mociño. 1893. Plantae Novae Hispaniae. 2a. ed. Secretaría de Fomento. México, D.F. 174 pp.

Sessé, M. y J. M. Mociño. 1894. Flora mexicana, 2a. ed., Secretaría de Fomento. México, D.F. 263 pp.

Smith, L. B. 1951. Studies in the Bromeliaceae, XVI. Contr. U.S. Natl. Herb. 29: 429-520.

Vellozo, J. M da C. 1825 [i. e. 1829]. Fl. flumin. 3: 132; Icones 1831. 3: t. 127. 